\title{
Responsabilidade Penal Ambiental no Mercosul e na América Central
}

\section{Indra Rojas Solano ${ }^{1}$}

SUMÁRIO: Introdução; Primeira Parte: Responsabilidade penal ambiental no Mercosul: 1. Mercosul e o Direito Ambiental; 2. Mercosul e responsabilidade criminal - Énfase no Brasil: 2.1. Normativas gerais; 2.2. Normativa específica - Segunda Parte: Responsabilidade Penal Ambiental na América Central: 1. América Central e o meio ambiente; 2. América Central e responsabilidade criminal; Conclusão; Bibliografia.

\section{IN'TRODUÇÃO}

O homem, através da história, sempre teve um relacionamento próximo com a natureza e é por isto que o direito introduz-se no âmbito ambiental mediante a proteção de seus elementos componentes.

A proteção refletida no ambiente nos séculos passados era especialmente individualista caracterizada pela "otimização unilateral de uma exploração orientada para os homens de uma forma meramente antropocêntrica ${ }^{2 "}$. Posteriormente, durante a Alta Idade Media, dáse certo nível de proteção ao meio ambiente coincidindo com os interesses de melhoria das condições de vida do homem. Nos últimos anos, a proteção ao meio ambiente tem adquirido maior importância, especialmente a partir da Conferência de Rio de Janeiro de 1992, onde se reconheceram mundialmente as crises ecológicas.

A regulação da responsabilidade por danos ao meio ambiente caracteriza-se por uma total ausência de uniformidade, tanto referida à sua conceituação, quanto a ser disciplinada pelo Direito Publico ou Privado, assim como em relação ao lugar que ocupa dentro dos ordenamentos jurídicos.

' Licenciada em Direito e Notariado pela Universidade Federada da Costa Rica e Mestranda em Direito Internacional pela Universidade Federal do Rio Grande do Sul - UFRGS.

2 ESER, Albin. "Derecho ecológico", Trad. De La Cuesta Arzamendi \& Sanz Morán, em: "Temas de Direito Penal e Procesal Penal" pág. 122, primeira edição Idemsa, Lima, 1998. 
Muitas áreas tornam-se relevantes e o comércio é um tema de grande importância dentro da temática ambiental por que "as políticas ambientais podem provocar distorções comerciais e as políticas comerciais podem gerar resultados ambientais negativos". Dentro das repercussões ambientais das políticas comerciais, encontram-se os acordos comerciais e, por isto, é que acordos regionais como o Mercosul e o Tratado de Livre Comércio da América Central não podem deixar de fora a questão ambiental. Para que um tema tão delicado tenha êxito dentro dos blocos regionais, a cooperação internacional em seu amplo sentido é indispensável.

Neste sentido, como bem faz menção o prof. MORA'TO4, em matéria ambiental, “o princípio de cooperação internacional, consagrado na Declaração de Estocolmo sobre o Meio Ambiente Humano de 1972 (princípio 21) - e posteriormente repetido na Declaração do Rio sobre o Meio Ambiente e Desenvolvimento de 1992 - enfatiza a responsabilidade dos países de velar para que as atividades realizadas dentro de sua jurisdição não causem danos ao meio ambiente dos outros Estados ou em áreas situadas fora dos limites das jurisdições nacionais, ao mesmo tempo em que resguarda a manutenção da soberania dos Estados na exploração dos seus recursos segundo suas próprias políticas ambientais". ${ }^{5}$

Tanto a tutela civil como a penal, resultam importantes dentro desta temática pela extrema relevância do bem-interesse protegido, tendo em vista - na área penal - que o impacto da criminalização, a peculiaridade do delinqüente ambiental ser de difícil identificação e o dano causado, na maioria das vezes, não ser imediatamente verificado, mas somente com o passar do tempo.

Pela importância do tema na atualidade é que encaminhamos esta pesquisa, para conhecer melhor a responsabilidade penal na aplicação dos instrumentos legais nos países da América Central e nos pertencentes ao bloco Mercosul.

O direito penal ambiental participa de todas as características do direito penal em termos genéricos; especificamente, o delito penal é a ação típica, antijurídica e culpável. Desta forma, temos que a determinação da existência de um delito penal deve observar a prática de uma conduta típica e antijurídica.

3 DEVIA, Leila." La Política Ambiental em el Marco Del Tratado de Asuncion" In: BERTUCCI Rosana, CUNHA Eldis, CUNHA Tarciso, DEVIA Leila, FIGUEIRAS Marcos, RUIZ DIAZ Roberto, VIDAL PERERA Raquel, Mercosur y Médio Ambiente, Ediciones Ciudad Argentina, Buenos Aires, 1996.

4 MORATO LEITE, José Rubens, Os instrumentos de proteção ambiental e o mercosul. In Revista dos Tribunais; São Paulo, 1996. V.725, P.39-48

5 No entender de Álvaro Luiz Valery Mirra, são pressupostos indispensáveis à efetivação deste principio "(A) o dever de informação de um Éstado aos outros Estados, nas situações críticas capazes de causar prejuízos transfronteiriços. B) o dever de informação e consultas prévias dos Estados a respeito de projetos que possam trazem efeitos prejudiciais aos países vizinhos". C) o dever de assistência e auxilio entre os países nas hipóteses de degradações ambientais importantes e catástrofes ecológicos. D) o dever de impedir a transferência para outros Estados de atividades ou substâncias que causem degradação ambiental grave ou que sejam prejudiciais à saúde humana - é o problema da exportação de poluição.VALERY, Álvaro Luiz Mirra In: MORATO LETIE, José Rubens, Os instrumentos de proteção ambiental e o mercosul. In Revista dos Tribunais; São Paulo, 1996. V.725, P.39-48 


\section{PRIMEIRA PARTE:}

\section{RESPONSABILIDADE PENAL AMBIENTAL NO MERCOSUL}

\section{MERCOSUL E O DIREITO AMBIENTAL}

Os países Argentina, Brasil, Paraguai e Uruguai celebraram, no dia 23.03.1991, o Tratado de Assunção, com o objetivo de dar a estes países uma maior integração e desenvolvimento, assim como novas perspectivas nas áreas econômica e comercial. Em outras palavras, e mais especificamente, como explica-nos a Dra. OLIVAR JIMÉNEZ estabelecer um Mercado Comum que iria implicar: "a livte circulação de bens, serviços e fatores produtivos, o estabelecimento de uma tarifa externa comum e de uma política comercial comum, a coordenação de políticas macroeconômicas e a harmonização das legislações. ${ }^{. "}$ "

Em 17.12.94, os seus integrantes tiveram uma reunião em Ouro Preto outorgando ao Mercosul personalidade jurídica. Neste mesmo ano, meses após, firmaram um Acordo de Sede, pactuando que a Secretaria Administrativa seria localizada em Montevidéu - Uruguai. "De lá para cá, houve avanços e recuos no Mercosul, tudo a depender de crises políticas internas e econômicas, sujeitando os Estado signatários aos efeitos da chamada globalização econômica"'.

O Tratado de Assunção não fez referência à questão ambiental, podendo-se afirmar que o Mercosul não é constituído por um Tratado com regras de proteção ambiental, exceto em seus considerandos, onde se menciona que o desenvolvimento econômico deve ser alcançado mediante o aproveitamento mais eficaz dos recursos disponíveis e à preservação do meio ambiente.

Os quatro países signatários deram o primeiro passo em direção à proteção do meio ambiente em Las Leñas, onde surgiu a denominada REMA - Reunião Especializada do Meio Ambiente - "encarregada de levar recomendações ao Grupo Mercado Comum que, se aptovadas, transformar-se-ão em Resoluções, com o intuito de estabelecer um âmbito específico para analisar a legislação dos Estados-membros em matéria ambiental, organizar políticas e coordenar a ação dos distintos subgrupos de trabalho em matéria ambiental".8.

- Olivar JimenEz, Martha Lucia. "El Establecimiento de una política común de protección al medio ambiente -su necesidad dentro de un mercado común" IN Revista Faculdade Direito UFRGS, Porto Alegre, 10: 100-119, jul. 1994.

7 PASSOS DE FREITAS, Vladimir. "Mercosul e Meio Ambiente" IN Direito Ambiental em Evolução, Editora Juruá, Curitiba, Brasil, 2001

8 BERTUCCI Rosana, CUNHA Eldis, CUNHA Tarciso, DEVIA Leila, FIGUEIRAS Marcos, RUIZ DIAZ Roberto, VIDAL PERERA Raquel, Mercosur y Médio Ambiente, Ediciones Ciudad Argentina, Buenos Aires, 1996 
A Reunião Especializada do Meio Ambiente - em diante REMA - na sua primeira reunião, considerando os princípios da gradualidade, flexibilidade e equilíbrio do Tratado de Assunção - princípios emanados da Declaração de Canela e da Conferência do Rio sobre Meio Ambiente e Desenvolvimento -, definiu como seu objetivo geral "a formulação de recomendações ao Grupo Mercado Comum, que assegurem uma adequada proteção do meio ambiente no matco do processo de integração regional que implica no Mercosul ${ }^{10 \%}$.

A partir de 1993, a REMA começou suas reuniões. Na sua terceira reunião, realizada em Brasília, foi aprovado o documento "Diretrizes Básicas em Matéria de Política Ambiental". Tal documento foi posteriormente aprovado pelo Grupo Mercado Comum, tendo se transformado na Resolução 10/94. Neste documento, adotarn-se políticas não degradantes ao meio ambiente, tecnologias próprias de reciclagem e do adequado tratamento dos resíduos, líquidos e gasosos, aproveitamento dos recursos naturais renováveis, etc. Em seu sexto encontro, o REMA foi convertido no $6^{\circ}$. Subgrupo de Trabalho do Mercosul (1992/1994), destinado a aprovar as diretrizes mínimas em matéria ambienta ${ }^{11}$.

Segundo o Prof. MORATO ${ }^{12}$, o Mercosul segue, desta forma, os passos da "União Européia, já que somente colocou diretrizes ambientais na sua reformulação de 1986 pelo chamado Ato Único Europeu - 17/12/1985. O Tratado da União Européia consagra como uma das políticas fundamentais da Comunidade a proteção do meio ambiente em seu artigo $3^{\circ}$.Desta forma, em princípio - no Mercosul - não houve maiores preocupações com a proteção do meio ambiente, o que só veio a ocorrer alguns anos após a assinatura do Tratado de Assunção".

Segundo SHEIBE ${ }^{13}$, são tarefas prioritárias (objetivos específicos) daquele $6^{\circ}$. Subgrupo de Trabalho: a) Harmonização ou diminuição das restrições não tarifárias; b) Regras que assegurem uma adequada competitividade, com análise do custo ambiental e do custo total do processo produtivo; c) Implementação da Série ISO-14000 - gestão ambiental, como fator favorável de competitividade dos produtos oriundos do Mercosul no mercado internacional; d) Criação de um sistema de informação ambiental; e) Criação do selo verde Mercosul.

9 GRADUALIDADE: não criar distorções econômicas graves, ir adaptando interesses econômicos com os sociais. FLEXIBILIDADE: ad́mitir retrocessos nos ritmos impostos por situações excepcionais EQUILÍBRIO: não pode haver prejuízo para uma parte e benefício desmedido de outra IN: LEME MACHADO, Paulo Affonso "Direito ambiental brasileiro" Malheiros Editores, 5 ed, 1995.

${ }^{10}$ MORATO LEITE, José Rubens. BUZAGLO DANTAS, Marcelo. Os instrumentos de proteção ambiental e o mercosul. In Revista dos Tribunais; São Paulo, 1996. V.725, P.39-48

11 IBIDEM,

12 Op. Cit. Pg. 48.

${ }^{13}$ SCHEIBE, Virginia da Cunha. Direito Ambiental no Mercosul, palestra proferida no IV Congresso de Direito ambiental promovido pelo Centro de Estudos Judiciários do Conselho da Justiça Federal, Brasília, 10.05.2001. 
Em face da dimensão dos problemas ambientais, haverá a necessidade dos blocos econômicos - incluindo-se o Mercosul - disciplinar a matéria ambiental, objetivando, segundo as palavras da Prof. Leila, "uma harmonização de duas propostas muitas vezes antagônicas: a liberalização do comércio e o desenvolvimento sustentável ${ }^{14 \text { ", }}$

Por exemplo, no caso do plantio de soja transgênica, que é liberada na Argentina e que no Brasil acabou sendo proibida, verifica-se uma certa incongruência. $O$ detalhe é que as legislações harmonizam-se e que o plantio não foi vedado pelo Poder Executivo ou pelo Legislativo brasileiros. Ao final, o Judiciário foi quem acabou proibindo através da exigência do estudo de impacto ambiental conforme decisão do Tribunal Regional Federal da $1^{2}$. Região ${ }^{15}$.

\section{MERCOSUL E RESPONSABILIDADE CRIMINAL - ÊNFASE NO BRASIL}

\subsection{Normativa gerais}

Para estudar este ponto, é relevante lembrar o conceito de responsabilidade como "a conseqüência jurídica decorrente do descumprimento de uma relação obrigacional. As pessoas são obrigadas a respeitarem-se mutuamente e a não ofenderem seus bens e valores, regra básica da convivência social. Ocorrendo uma lesão, há de se analisar se o dano restringiu-se à órbita civil ou atingiu algum bem protegido por uma norma penal ${ }^{16 \%}$.

O legislador, ao fazer a configuração tipológica dos crimes contra o meio ambiente, afastou-se substancialmente dos padrões sobre os quais se assentava o Direito Penal tradicional.

O legislador ambiental tem a difícil tarefa de antecipar o momento de consumação do delito, ganhando em eficiência, posto que o dano ambiental, pela sua complexidade, é de difícil constatação e reparação, quando não totalmente irreparável. Assim como no âmbito ambiental a norma penal possui vocação fundamentalmente direcionada para uma posição de prevenção do dano, adotando, desta forma, um princípio de precaução.

Pela importância da temática, é que um bloco tão poderoso como o Mercosul não pode excluir-se da regulamentação da responsabilidade por dano ambiental. Ainda que em diferentes normativas, a legislação dos quatro países - Argentina, Brasil, Uruguai e Paraguai - inclui os seguintes princípios básicos:

- O dever de preservar o ambiente;

- A obrigação de recompor o ambiente danificado;

- A obrigação de indenizar.

${ }^{14}$ DEIVA, Leila. Op cit., p. 5.

${ }^{15}$ BRASIL, Tribunal Regional Federal da $1^{\mathrm{a}}$. Região, AC 2000.01.00.014661-1/DF, 2T., rela. Juíza Assusete Magalhães, j. 08.08.2000.

${ }^{16}$ Fernando Brandini Barbagalo, "Responsabilidade dos entes jurídicos", In: http:// www.advogadoctiminalista.com.br/home/artigos/0047.html. 
Para uma melhor compreensão, vejamos especificamente as normas gerais de cada um dos países do Mercosul:

Argentina: Em seu art. 41, a Constituição Nacional de Argentina protege o direito dos seus habitantes a um ambiente ecologicamente equilibrado, conferindo poder às autoridades para a proteção de tal direito ${ }^{17}$.

Note-se que na Argentina não encontramos uma definição específica do que seja dano ambiental.

Paraguai: O art. $8^{\circ}$ da Constituição do Paraguai de 1992: “Todo dano ao ambiente importará à obrigação de recompor e indenizar". Aqui, a Constituição Paraguaia adota o Princípio do Poluidor-Pagador, que é base do Direito Ambiental.

A Lei no. 96/92 (Vida Silvestre): Art. $4^{\circ}$. .: "Todo dano ao ambiente importará à obrigação de recompor e indenizar".

A Lei no. 352/94 (Áreas Silvestres Protegidas): Art. 2': "Todos os habitantes, as organizações privadas e as instituições do Estado têm a obrigação de salvaguardar as Áreas Silvestres Protegidas".

Uruguai: A Constituição de Uruguai estabelece: "A proteção do meio ambiente é de interesse geral. As pessoas deverão abster-se de qualquer ato que cause depredação, destruição ou contaminação graves ao meio ambiente. A lei regulamentará esta disposição e poderá prever sanções para os infratores".

A Lei 16.466/94 (declara de interesse geral a proteção do meio ambiente contra qualquer tipo de depredação, destruição ou contaminação) - Art. 4": "Sem prejuízo das sanções administrativas e penais que indique a lei, quem provocar a depredação, a destruição ou a contaminação do meio ambiente em violação ao estabelecido pelos artigos da presente lei será civilmente responsável por todos os prejuízos que ocasione, fazendo-se responsável, além disto, se materialmente isto for possível, pelas ações conducentes à sua recomposição. Quando os prejuízos ocasionados por dita violação forem irreversíveis, o responsável dos mesmos deverá encarregar-se de todas as medidas tendentes à sua máxima redução ou mitigação, sem prejuízo das responsabilidades administrativas, civis ou penais que possam corresponder".

${ }^{17}$ Art. 41. CONSTITUIÇÃO NACIONAL DE ARGENTINA "Todos os habitantes têm direito a um ambiente sano, equilibrado, apto para o desenvolvimento humano e para que as atividades produtivas satisfaçam as necessidades presentes sem comprometer as das gerações futuras; e tem o dever de preservá-la. As autoridades proverão á proteção deste direito, á utilização racional dos recursos naturais, á preservação do patrimônio natural e cultural e da diversidade biológica, e á informação e educação ambiental. Corresponde à Nação ditar as normas que contem os pressupostos mínimos de proteção e ás "provincias" às necessárias para complementa-as, sem que aquelas alteram as jurisdições locais". 
Brasil: Em seu art. 225, a Constituição Brasileira contempla o direito a um meio ambiente ecologicamente equilibrado, definindo-o como um bem de uso comum e esclarecendo que é dever do Poder Público e da coletividade a defesa do mesmo ${ }^{18}$.

$\mathrm{Na}$ Lei 6.938/81, dispõe-se sobre a Política Nacional do Meio Ambiente, seus fins e os mecanismos de formulação e aplicação ${ }^{19}$.

Deve destacar-se que a legislação de Brasil, através de sua Lei 6938/81 (sobre disposições políticas nacionais do meio ambiente), contém uma longa lista de dispositivos acerca da matéria, os quais estabelecem princípios para a proteção e o equilíbrio ecológicos ainda que não correspondam estritamente à responsabilidade ambiental.

Por sua parte, o Brasil faz uma definição de impacto ambiental na Resolução CONAMA 001/86, no seu art. $1^{\circ}$, como "...qualquer alteração das propriedades físicas, químicas e biológicas do meio ambiente, causada por qualquer forma de matéria ou energia resultante das atividades humanas que direta ou indiretamente afetam: a saúde, a segurança e o bemestar da população, as atividades sociais e econômicas, a biota, as condições estéticas e sanitárias do meio ambiente e a qualidade dos recursos ambientais", assim como faz uma lista de definições com vários conceitos de danos ambientais.

Assim como a própria Lei 6.938/81 (que dispõe sobre a Política Nacional do Meio Ambiente, seus fins e os mecanismos de formulação e aplicação e da outras providências) traz uma lista de definições de diversos danos ambientais ${ }^{20}$

${ }^{18}$ Art. 225 CONSTITUIÇÃO DA REPÚBLICA FEDERATIVA DO BRASIL "Todos têm direito ao meio ambiente ecologicamente equilibrado, bem de uso comum do povo essencial à sadia qualidade de vida, impondo-se ao Poder Público e à coletividade o dever de defendê-lo e preservá-la para as presentes e futuras gerações... $3^{a}$ As condutas e atividades consideradas lesivas ao meio ambiente sujeitarão os infratores, pessoas físicas ou jurídicas, a sanções penais e administrativas, independentemente da obrigação de reparar os danos causados..."

${ }^{19}$ Lei 6938/81. REPUBLICA FEDERATIVA DO BRASIL Art. $2^{\circ}$.: "A Política Nacional do Meio Ambiente tem por objetivo a preservação, melhoria e recuperação da qualidade ambiental propícia à vida, visando assegurar, no País, condições ao desenvolvimento sócio - econômico, aos interesses da segurança nacional e à proteção da dignidade da vida humana, atendidos os seguintes princípios:

1- ação governamental na manutenção do equilíbrio ecológico, considerando o meio ambiente como um patrimônio público a ser necessariamente assegurado e protegido, tendo em vista o uso coletivo;

${ }^{20}$ Art. $3^{\circ}$.: "Para os fins previstos nesta Lei, entende-se por:

...II - Degradação de qualidade ambiental: a alteração adversa das características do meio ambiente;

III - Poluição: a degradação da qualidade ambiental resultante de atividades que direta ou indiretamente prejudiquem a saúde, a seguranç̧a e o bem-estar da população, criem condições adversas às atividades sociais e econômicas, afetem desfavoravelmente a biota, afetem as condições estéticas ou sanitárias do meio ambiente e lancem matérias ou energia em desacordo com os padrões ambientais estabelecidos. III - planejamento e fiscalização dos usos dos recursos ambientais;

IV - proteção dos ecossistemas, com preservação de áreas representativas;

$\mathrm{V}$ - controle e saneamento das atividades potenciais ou efetivamente poluidoras;

VI - incentivos ao estudo e è pesquisa de tecnologias orientadas para o uso racional e à proteção dos recursos ambientais; 
Desta forma, confirma-se, ainda que de forma muito genérica e em diferentes redações e legislações, que os quatro países do Mercosul apresentam uma estrutura jurídica consciente da importância da conservação e preservação do meio ambiente e das regulamentações em questões ambientais.

Em um âmbito específico, as legislações dos quatro países pertencentes ao Mercosul contemplam, mesmo que de maneira precária, sanções penais, mas com âmbitos de aplicação diferentes. É importante neste ponto, fazer menção que a Argentina e o Uruguai dão maior ênfase às sanções quando o particular contamina ou envenena as águas de uma forma perigosa para a saúde, não tanto como para as sanções contra as agressões à flora $e$ à fauna, sendo que o Brasil é o país com maior legislação a este respeito no bloco tegional ainda que sua legislação contra a contaminação das águas seja muito genérica.

Por outta parte, a Lei 716/95 do Paraguai tipifica diversas condutas danificadoras do meio ambiente, as quais são apenadas com multa e prisão.

Vejamos, portanto, as diversas legislações sobre a responsabilidade ambiental nos países do Mercosul.

\subsection{Normativa específica}

\section{Argentina:}

O Código Penal Argentino, em seu art. 200, impõe pena de prisão de 3 a 10 anos a quem envenene ou adultere as águas potáveis de maneira que se torne perigoso para a saúde, assim como as substâncias alimentícias ou medicinais destinadas ao consumo da coletividade, agravando a pena no caso de morte da vítima ${ }^{21}$.

Em seu art. 55, a Lei 24.051 sanciona com as mesmas penas do artigo 200 do Código Penal aquele envenena ou contamina o solo, a água, a atmosfera ou o ambiente em geral, utilizando resíduos perigosos e aumentando também a pena caso a vítima venha a falecer. ${ }^{22}$

VII - acompanhamento do estado da qualidade ambiental;

VIII - Recuperação de áreas degradadas;

IX - proteção de áreas ameaçadas de degradação;

$X$ - educação ambiental a todos os níveis do ensino, inclusive a educação da comunidade, objetivando capacitá-la para participação ativa na defesa do mejo ambiente."

${ }^{21}$ Art. 200. "Será reprimida com reclusão ou prisão de 3 a 10 anos, o que envenene o adultere, de um modo perigoso para a saúde, águas potáveis ou substâncias alimentícias ou medicinais, destinadas ao uso público ou ao consumo de uma coletividade de pessoas. Se o fato fosse seguido pela morte da alguma pessoa, a pena será de 10 a 25 anos de reclusão ou prisão" CODIGO PENAL DA REPUBLICA ARGENTINA.

22 Art. 55 "Será reprimidas com as mesmas penas estabelecidas num artigo 200 do Código Penal, o que, utilizando os resíduos (perigosos) a que se refere a presente lei, envenene, adultere o contamine de um modo perigoso para a saudade, o solo, a água, a atmosfera ou o ambiente em geral. Se o fato fosso seguido da morte de alguma pessoa, a pena será de 10 a 25 anos de reclusão ou prisão"'. LEI 24051 da República Argentina. 
Dentro da mesma legislação, o seu art. 57 faz referência à imposição de sanções aos diretores, administradores, mandatários ou representantes da pessoa jurídica que cometam os delitos anteriormente mencionados. ${ }^{23}$

\section{Paraguai:}

No seu Código Penal, o art. 260 sanciona com pena de 3 a 7 anos de prisão quem coloque em perigo a saúde das pessoas por meio da contaminação das águas ou qualquer coisa destinada a alimentação pública, agravando-se a pena para o máximo de 15 anos na morte da vítima. ${ }^{24}$

A Lei 352/84, no seu art. 58, indica que as violações às áreas silvestres protegidas serão consideradas atentatórias contra o bem social e terão caráter de delito de ação penal ${ }^{25}$.

Na Lei no. 716/95 estabelecem-se sanções tanto de prisão como de multa para atividades diversas não especificadas, entre estas:

a) A queima de bosques ou formações vegetais que prejudiquem gravemente o ecossistema;

b) A exploração florestal de bosques declarados especiais ou protetores;

c) O tráfico ou comercialização ilegal de madeira ou seus derivados; e

d) Qualquer alteração do regime de controle das águas, sem autorização expressa da autoridade competente.

Assim como no seu art. 5, sancionam-se outras atividades não especificadas, entre elas:

a) A destruição das espécies de animais silvestres em vias de extinção e...

b)...

c) A alteração ou falsificação de estudos e avaliações de impacto ambiental;

d) Os que elidam as obrigações legais referentes à medidas de mitigação do impacto ambiental.

${ }^{23}$ Art. 57 "Quando algum dos fatos previstos nos dois artigos anteriores se tiverem produzido por decisão de uma pessoa jurídica, a pena se aplicará aos diretores, gerentes, síndicos, membros do conselho de vigilância, administradores, mandatários o representantes da mesma que tivessem intervindo ao fato punível, sem prejuízo das demais responsabilidades penais que possam existir". LEI 24051 da República Argentina.

${ }^{24}$ Art. 260 "Quem coloque em perigo a vida ou saúde das pessoas corrompendo o envenenando a água potável para uso comum, ou qualquer coisa destiriada à alimentação pública, será castigado com penitenciária de três a sete anos. Se resultar a morte de uma o mais pessoas, a pena será de seis a quinze anos de penitenciária". CODIGO PENAL REPÚBLICA DE URUGUAI

${ }^{25}$ Lei $352 / 84$, Art. 58 As violações ao disposto por esta lei serão consideradas como atentatórias contra um bem social e terão caráter de delito de ação penal pública. REPÚBLICAORIENTAL DE URUGUAI 


\section{Uruguai:}

No Código Penal, de forma semelhante às legislações Paraguaia e Argentina, o art. 218 sanciona quem adultere ou envenene águas ou substâncias destinadas à alimentação da coletividade. ${ }^{26}$

Destaca-se que o Uruguai é o país mercosulino com menor legislação penal com sanções para os delitos penais ambientais, sendo a maioria de suas represálias de caráter civil ou administrativo.

\subsection{Responsabilidade penal ambiental no Brasil:}

O Brasil, na condição de país que detém a maior floresta tropical do mundo e uma incomparável biodiversidade na flora e na fauna, sofre uma grande pressão internacional para a proteção do meio ambiente.

Apesar disto, não se encontra legislação no Código Penal, mas, em compensação, o Código Florestal brasileiro estabelece no seu art. 26: "Constituem contravenções penais, puniveis com três meses a um ano de prisão simples ou multa de uma a cem vezes o saláriominimo mensal do lugar e da data da infração ou ambas as penas cumulativamente: destruir ou danificar a floresta considerada de preservação permanente, mesmo que em formação, ou utilizá-la com infringência das normas estabelecidas ou previstas nesta Lei; cortar árvores em florestas de preservação permanente, sem permissão da autoridade competente; causar danos aos Parques Nacionais, Estaduais ou Municipais, bem como às Reservas Biológicas; impedir ou dificultar a regeneração natural de florestas e demais formas de vegetações;..."

Cabe destacar que para as infrações de menor potencial são aplicáveis as disposições do art. 76 da Lei 9.099/95, que trata da aplicação imediata da pena.

Sem embargo, a base da responsabilidade penal ambiental está disposta na Lei no. 9.605/98, que materializou a exigência legal prevista na Constituição Federal.

A referida lei teve origem na Câmara dos Deputados e foi publicada em 13/02/199 corn o veto presidencial ao art. 81, entrando em vigor 45 dias após.

Do estudo da legislação, verifica-se que alguns tipos penais por ela não abrangidos, como o do art. 13 da Lei 8.974/95 (Biossegurança), arts. 50/51 e a Lei 6.766/79 (parcelamento do solo urbano).

${ }^{26}$ Art. 218 Quem envenenar o adulterar em forma perigosa para a saúde, as águas ou substâncias destinadas à alimentação pública, com o sem lesão efetiva de tais bens, será castigado com doce meses de prisão a dezesseis anos de peniteneiária. CODIGO PENAL REPÚBLICA ORIENTAL DE URUGUAI. ART 218. 
Esta lei trouxe algumas novidades para a legislação brasileira, entre elas se encontram²7:

1.Unificação, em um só texto, da maioria dos crimes ambientais;

2. Uniformização do trato dos bens ambientais, considerando todos os atentados como crimes e utilizando os mesmos critérios para a definição das penas aplicáveis;

3. Responsabilização penal da pessoa jurídica (Art. $3^{\circ}$.);

4.Participação por omissão do dirigente da pessoa jurídica;

5. Valorização das penas altetnativas (art. $7^{\circ}$.), havendo a possibilidade de substituição para penas inferiores a 4 anos;

6. Possibilidade de transação ou suspensão do processo em todos os casos (exceção do art. 41);

7. Preocupação com a reparação do dano ambiental ${ }^{28}$.

Neste ponto, a responsabilidade penal ambiental das pessoas jurídicas é um tema muito controvertido no mundo jurídico penal. Alguns autores sustentam que a responsabilidade penal da pessoa jurídica nos crimes ambientais trata da responsabilidade objetiva, que vai de encontro com os princípios basilares da culpabilidade e da responsabilidade pessoal ${ }^{29}$. Para eles, o art. $3^{\circ}$. da Lei $9.605 / 98$ está eivado de inconstitucionalidade. Outros, todavia, sustentam a constitucionalidade e aceitam a aplicação de penas às pessoas jurídicas à exceção das privativas de liberdade, que possuem caráter pessoal ${ }^{30}$. Vejamos o artigo específico que condena penalmente as pessoas jurídicas pela prática de crimes ambientais:

Art 30. (Lei 9.605/98): "As pessoas jurídicas serão responsabilizadas administrativa, civil e penalmente conforme o disposto nesta Lei, nos casos em que a infração seja cometida por decisão de seu representante legal ou contratual, ou de seu órgão colegiado, no interesse ou benefício de sua entidade".

A Prof. Silva Cappelli ${ }^{31}$ nos dá uma resposta a esta questão, afirmando que esse capítulo apresenta vários óbices:

${ }^{27}$ CAPPELLI, Silvia. Aulas proferidas na cadeira de direito ambiental dentro do curso preparatório à carreira do Ministério Público, Porto Alegre/RS, 2002.

${ }^{28}$ Neste sentido ver a CAPELLI, Silvia, op cit. Quem nos explica neste ponto "É condição para o sursis especial (Art. 17) a perícia de constatação do dano, sempre que possível, fixará o montante do prejuízio causado (Art. 19), a sentença fixará o vaíor mínimo para a reparação dos danos sofridos pelo ofendido e pelo meio ambiente. A transação é condicionada à previa composição dos danos (art.27), a declaração da extinção da punibilidade (suspensão do processo) é condicionada à comprovação da reparação do dano através de laudo de constatação (Art.28).

29 PRADO, Luiz Régis. Crimes Contra o Ambiente. São Paulo: RT, 1998, p.20.

30 SIRVINKAS, Luís Paulo. Tutela Penal do Meio Ambiente. São Paulo: Saraiva, 1998, pp 22-23; MACHADO, Paulo Affonso Leme. Direito Ambiental Brasileiro 7 ed. São Paulo: Malheiros, 1998, pp 593-598.

${ }^{31}$ CAPELLI, Silvia. Op cit. p. 26. 
- Incapacidade de ação e de pena;

- O conceito de culpabilidade é distinto para a pessoa física e para a pessoa jurídica;

- A potencial consciência da ilicitude só é exigível da pessoa física;

- Ferimento ao princípio da personalidade da pena (Onde se afirma que os sócios recebem os efeitos patrimoniais da pena, assim como se beneficiam dos lucros decorrentes da prática delituosa);

- Inutilidade das sanções administrativas em razão da possibilidade de responsabilizar o dirigente.

$\mathrm{O}$ art. $3^{\circ}$, ao não fazer diferenciação se a pena aplicável a pessoa jurídica de direito público ou pessoa jurídica de direito privado, traz inúmeros problemas na sua utilização, já que tradicionalmente a pessoa jurídica de direito público não é suscetível de responsabilização penal.

Entretanto, a tese pela constitucionalidade do art. $3^{\circ}$. é a corrente que possui o maior número de defensores na doutrina.

Neste contexto, alguns países já se anteciparam neste sentido. A França ${ }^{32}$ esclarece melhor este ponto, prevendo em seu Código Penal de 1994 o princípio da responsabilidade penal das pessoas jurídicas, sem excluir as pessoas físicas; ainda, esclarece que somente as pessoas jurídicas de direito privado são responsáveis penalmente. Infelizmente, a Lei 9.605/ 98 não contém vedação à responsabilidade penal da pessoa jurídica de direito público.

Mas não somente a França nos traz este exemplo. Também países como os Estados Unidos da América, Inglaterra, Canadá, Holanda, Austrália, Portugal, Bélgica, Suécia e Irlanda do Norte têm admitido que as pessoas jurídicas possam responder penalmente pelos danos que ocasionam ao meio ambiente.

No Brasil, a doutrina de SÉRGIO SHECAIRA ${ }^{33}$ e GUILHERME PURVIN FIGUEREIDO ${ }^{34}$ não admite a responsabilidade penal da pessoa jurídica de direito público, por que as sanções penais são incompatíveis com as finalidades do Estado.

Por sua parte, outros autores afirmam que a impossibilidade de responsabilizar um ente jurídico penalmente se deve ao fato de não poder imputar-se às pessoas que não sejam

${ }^{32}$ Entre os delitos que podem ser imputados às pessoas jurídicas francesas estão: atentado ao sistema de tratamento automatizado de dados (Código Penal Francês, artigos 414-7 e artigo 422-5); abandono de lixo e rejeitos (artigo R632-1 e artigo R635-8); infraçōes em matéria de pesquisa biomédica (artigo L20919-1, do Código de Saúde Francês).

${ }^{33}$ SHECARIA, Sérgio Salomão - Responsabilidade penal da pessoa jurídica, $1^{\text {a }}$ ed., $2^{\text {a }}$ tiragem. São Paulo: Revista dos Tribunais, 1999

${ }^{34}$ PURVIN DE FIGUEIREDO, Guilherme. "Crimes ambientais e responsabilidade penal objetiva" IN: http:/ /www.direitopenal.adv.br/artigos.asp?pagina $=2.2 \&$ id $=697$ 
físicas por contrariar o conceito tradicional de que imputabilidade surge com a capacidade de entendimento do sujeito ativo com relação ao possível crime cometido (neste sentido, lembremos que a imputabilidade reside na capacidade de entendimento da conduta delituosa que foi praticada e a determinação volitiva adequada a esse entendimento).

A saber, RENE ARIEL DOTTI ${ }^{35}$ a firma que, no sistema jurídico positivo brasileiro, a responsabilidade penal é atribuída exclusivamente às pessoas físicas. Os crimes delitos ou contravenções não podem ser praticados pelas pessoas jurídicas, posto que imputabilidade jurídico-penal é uma qualidade inerente aos seres humanos.

Para CEZAR ROBERTO BITTENCOURT " "O Direito Penal fundamenta-se na culpabilidade, cuja conduta, somente é atribuível ao homem, pedra angular da Teoria Geral do Crime".

Contudo, apesar de aceitar a doutrina tradicional, muitos doutrinadores contrários têm admitindo a responsabilidade penal da pessoa jurídica como criminalidade não convencional, dentre os quais: JOÃO MARCELLO DE ARAÚJO JÚNIOR ${ }^{37}$, VLADIMIR PASSOS DE FREITAS E GILBERTO PASSOS DE FREITAS ${ }^{38}$, TOSHIO MUKAI ${ }^{39}$, PAULO AFFONSO LEME MACHADO ${ }^{40}$, etc.

A Doutrina não chega a um consenso nesta matéria, encontrando-se sumamente dividida, sem manifestações dos tribunais superiores sobre o assunto, portanto, aguardando uma decisão que unifique as posições.

Dentre os requisitos para a aplicação da responsabilidade penal da pessoa jurídica encontramos:

1. Infração praticada no interesse da empresa e em seu benefício. Deve trazer lucro ou benefício de qualquer ordem. Quando praticado no interesse exclusivo do agente (art. $2^{\circ}$.), 0 crime é da pessoa física;

2. Vinculação entre $\mathrm{o}$ ato praticado e a atividade da empresa;

3. Liame hierárquico entre a empresa e o executor (autor material);

4. Deve ser utilizada a estrutura física da empresa. O crime sé pode ocorrer diante da existência da pessoa jurídica.

${ }^{35}$ Dotti, René Ariel, A responsabilidade Penal das Pessoas Jurídicas, Revista de Ciências Criminais n. 11, São Paulo, pág. 201

36 Bittencourt, Cezar Roberto. Responsabilidade Penal da Pessoa Jurídica, Boletim do IBCCrim, São Paulo, abril/98, n. 65, pág. 7.

${ }^{37}$ ARAUJO, João Marcello de, Regionalizaçẫo do direito penal no Mercosul (Contribuição para a Historia Jurídica do Mercosul) in Revista de Derecho del Mercosur. Buenos Aires, La Ley, 1997.

${ }_{38}$ PASSOS DE FREITAS, Vladimir. Mercosul e Meio Ambiente IN Direito Ambiental em evolução, Editora Juruá, Curitiba, Brasil, 2002.

${ }^{39}$ MUKAI, Toshio, Direito Ambiental Sistematizado, Forense Universirária, $1^{a}$ edição, 1992, Rio de Janeiro, p. 79.

40 Paulo Affonso Leme Machado Direito Ambiental Brasileiro, ed. Malheiros, $4^{2}$ edição, São Paulo, p. 35. 
É importante lembrar que o Direito Penal busca evitar a prática de delitos, razão pela qual as pessoas que não agem para impedi-los, tornam-se partícipes. Neste sentido é que opera o art $2^{\circ}$. da nova lei, o qual estabelece a responsabilidade do diretor, administrador, membro de conselho e de órgão, técnico, administrador, membro de conselho e de órgão técnico, auditor, gerente, preposto ou mandatário de pessoa jurídica, que, sabendo da conduta criminosa de outrem, deixa de impedir a sua prática, quando podia agir para evitá-la.

As sanções para as pessoas jurídicas serão de acordo com o artigo 21: a multa, a restrição de direitos ${ }^{41}$ e a prestação de serviços à comunidade ${ }^{42}$.

A resposta penal, como meio dissuasório, não é totalmente eficaz para lograr a verdadeira finalidade de uma política adequada do meio-ambiente, isto é, a reparação integtal do dano ambiental causado. A aplicação de medidas restritivas da liberdade das pessoas ou a imposição pelas autoridades administrativas competentes de elevadas sanções pecuniárias são instrumentos necessários para prevenir atentados ao meio ambiente, porém, tais soluções a priori precisam de um adequado complemento a posteriori, quando o dano já se tenha materializado, com a intenção de uma possível restauração do estado das coisas.

\section{SEGUNDA PARTE: RESPONSABILIDADE PENAL AMBIENTAL NA AMÉRICA CENTRAL}

\section{AMÉRICA CENTRAL E O MEIO AMBIENTE}

A América Central, como "ponte das Américas", com importantes redutos de bosques tropicais úmido, com uma riqueza hidráulica invejável e muita diversidade ecológica, apresenta-se diante do mundo como uma região de alto potencial natural. Desta forma, os governos têm incentivado altamente a conservação do meio ambiente nas últimas décadas.

$\mathrm{Na}$ região centro-americana, diante da problemática ambiental e levando-se em consideração a diversidade de cada um dos países que a compõe, tem-se buscado estabelecer alguns mecanismos para o melhoramento de campos específicos no setor ambiental.

Podemos mencionar, por exemplo, o tema do comércio e ambiente, no qual se tem utilizado medidas de redução dos impactos ambientais e o incremento da proteção ambiental juntamente com a consideração do desenvolvimento sustentável. Assim, destaca-se que entre 1989 e 1994 firmaram-se os seguintes convênios: a) Convênio Centro-americano para

${ }^{41}$ Art. 22 - As penas restritivas de direito a pessoa jurídica são: I.Suspensão parcial ou total de atividades; II. Interdição de estabelecimento, obra ou atividade. III. Proibição de contratar com o Poder Público, bem como dele obter subsídios, subvenções ou doações

${ }^{42}$ Art. 23 - A prestação de serviços à comunidade pela pessoa jurídica consistirá em: I. Custeio de programas e projetos ambientais; II. Execução de obras de recuperação de áreas degradadas; III. Manutenção de espaços públicos; IVContribuições a entidades ambientais ou culturais públicas. 
a Proteção do Ambiente (CCAD), no qual se identificam as principais preocupações, lineamentos gerais e o marco institucional para a prática de medidas no campo ambiental, assim como, a estruturação do plano de ação floresta da América Central, b) o Convênio para a Conservação da Biodiversidade e Proteção das Áreas Silvestres Prioritárias na CentroAmérica (CCAP), c) o Convênio Centro-Americano de Bosques e o Convênio Regional sobre o Câmbio Climático, d) a Aliança para o Desenvolvimento Sustentável (ALIDES) e e) a Convenção Intetnacional de Espécies Ameaçadas de Fauna e Flora silvestre, denominada CITES, que proíbe o comércio de espécies ameaçadas de extinção, onde estima-se que a cooperação internacional é fundamental para obter a proteção das espécies.

Mas, a despeito destas decisões, ainda que possam servir para reforçar a proteção sobre bens comuns da humanidade, como as águas, o câmbio climático e a proteção da camada de ozônio, existem outros temas como o crescimento demográfico, as migrações, a urbanização não planificada, o déesenvolvimento insustentável da indústria e o turismo, que continuam afetando a maioria das regiões na América Central.

Sobre a proteção da camada de ozônio, a Convenção de Viena (Lei no. 7228) busca reduzir a destruição do ozônio. Esta Convenção tem por objetivo a proteção da saúde humana $\mathrm{e}$ ambiental contra os efeitos adversos que possam surgir à modificação da camada de ozônio. Na Costa Rica, por exemplo, tem-se proibido os aerossóis e os gases propelentes. As empresas fabricantes de aerossóis deverão escolher o tipo de propelente a usar nas indústrias desde que não danifiquem o meio ambiente.

$\mathrm{Na}$ Centro-América, o tema ambiental, como em todo o continente, tem sido administrado ampla e basicamente pelo Estado, instituindo-se inúmeras normativas não somente gerais, como específicas, com vistas à resolução da problemática ambiental. Encontramos disposições referentes à caça, pesca, recursos florestais, proteção das águas, assim como dos bosques, o ar, a zona marítimo terrestre, e os recursos minerais, todos estes tendo regulamentações e políticas orientadas, em sua maioria, à sua promoção, mas também com a adoção de disposiçōes sancionadoras.

No entanto, verificamos que existem problemas que se agravam como o corte excessivo das árvores, refletindo em um desmatamento de 45 hectáreas por hora no istmo. ${ }^{43}$ Um dos motivos responsáveis por estes problemas é o fato de as políticas ambientais emanadas das instituições públicas centro-americanas terem sido mais destinadas ao controle do que à prevenção, educação ou participação.

Diante deste quadro, deduzimos que a Centro-América, enquanto um istmo regional, comercial e político, tem-se preocupado pela situação negativa em face do meio ambiente,

${ }^{43}$ União Mundial da Natureza, Oficina Regional de Mesoamérica, Banco Mundial. A Centro-américa florestal do futuro e o Bando Mundial. Resultados da consulta centro-americana sobre a estratégia e aplicação das políticas florestais de 1991 do Banco Mundial. São José, abril do 2000. 
tomando medidas de cooperação internacional, estudos sobre o impacto ambiental através do Projeto de Fortalecimento dos sistemas de Avaliação de Impacto Ambiental (EIA) na Guatemala, Nicarágua e Costa Rica. Trata-se de um projeto executado pela União Mundial para a Natureza (UICN), sob a coordenação da "Comissão Centroamericana de Ambiente y Desarrollo" (CCAD), e financiado pelo Governo de Holanda.

Contudo, ainda deve-se adotar uma política regional a respeito do fomento de práticas de consumo sustentável, como estabelece o capítulo $4^{\circ}$. da Agenda 21, que vem sendo promovido pela organização Consumers International.

\section{AMÉRICA CENTRAL ${ }^{44}$ E RESPONSABILIDADE CRIMINAL}

O direito ambiental penal desenvolveu-se de forma relevante na década de 90, de maneiras diversas: através de disposições que são incorporadas em leis setoriais protetoras de certos recursos naturais ou em leis gerais ambientais ou em Códigos penais ou, ainda, mediante a expedição de leis ambientais penais especiais.

No caso da legislação penal ambiental centro-americana, as disposições têm sido expedidas de forma casuística, muitas vezes sem contar com os requisitos fundamentais que devem estar presentes nas disposições penais, tais como a tipicidade, imputabilidade, etc. Poder-se-ia afirmar que, em termos gerais, o Direito Ambiental tem uma presença importante na presente década. Todavia, há um problema: a pouca aplicação e cumprimento das disposições normativas. Portanto, na análise da eficácia da legislação penal ambiental, existe uma marcante tendência à impunidade das violações a essas disposições. Diante desta impunidade, várias razões devem ser consideradas, entre elas, o descobrimento de um tema, que ainda podemos denominar de novo - Direito Ambiental - e que requer o ajuste dos princípios tradicionais do Direito Penal devido ao seu caráter preventivo frente aos prejuízos ao ambiente.

Estudemos, portanto, as legislações ambientais de cada um dos países pertencentes à América Central e as penalidades impostas aos delitos penais ambientais.

\section{Guatemala:}

A Guatemala, como país com maior extensão territorial e com maior população na Centro-América (aprox. 12 milhões de habitantes), conta com uma grande responsabilidade no que diz respeito à educação ambiental para a população. Assim, como representa $44 \%$ da população indigena no istmo centro-americano, é o coração das ruínas e cultura indigena e, por isto, é o país com maior preocupação na devida regulamentação da preservação, tanto da natureza, como da arqueologia através da sua legislação.

\footnotetext{
${ }^{44}$ Não está incluído Belize por se tratar de um país recentemente e pela escassa legislação sobre o tema.
} 
A Constituição Política da República da Guatemala estabelece, no seu artigo 97, que o Estado, Municípios e habitantes estão obrigados a propiciar o desenvolvimento social, econômico e tecnológico que evite a contaminação do ambiente e mantenha o equilíbrio ecológico ${ }^{45}$.

Assim como o inciso 'c' do artigo 119 (do mesmo corpo normativo) indica-nos como obrigação do Estado, adotar as medidas necessárias para a conservação, desenvolvimento e aproveitamento dos recursos naturais de forma eficiente.

A Guatemala apresenta como lei marco sobre a roteção dos recursos naturais a Lei para a proteção e o melhoramento do meio ambiente de $\quad 86$. No entanto, a responsabilidade penal ambiental encontra-se tipificada no Código Penal, nos artigos 346 a 347--E.

O art. 346 sanciona a exploração ilegal doa recursos naturais, impondo prisão ou multa a quem - sem estar devidamente autorizado - explorar comercialmente os recursos naturais encontrados no mar territorial ou na plataforma marítima, assim como os rios, lagunas, etc.

$\mathrm{O}$ art. 347 sanciona os delitos praticados contra os recursos florestais com pena de prisão ou multa. $\mathrm{O}$ art. 347-A sanciona penalmente a contaminação do ar, solo ou sonora, por quem utiliza substâncias perigosas para o homem ou aos animais. Art. 347-B: impõe prisão ao diretor, administrador, gerente, titular ou beneficiário, que autorize alguma atividade comercial que contamine o ar, os solos ou as águas. Art. 347-C: indica as mesmas penas de prisão ou multa ao funcionário público que aprove a instalação de uma exploração industrial. Art. 347 - D: sanciona as pessoas que exercem o corte ilegal de árvores.

Cabe destacar que, nos países da América Latina, a legislação florestal ocupa um capítulo especial, e a Guatemala não tem sido a exceção. A Lei Florestal ${ }^{46}$ da Guatemala foi publicada após uma longa e complexa discussão, em 04 de dezembro de 1996, contemplando diversos crimes contra a floresta e o meio ambiente e sancionando administrativamente os seus praticantes.

45 Art. 97 CONSTITUIÇÃO POLÍTICA "O Estado, as municipalidades os habitantes do território nacional, estão obrigados a propiciar o desenvolvimento social, econômico e tecnológico que preverá a contaminação do ambiente e mantenha o equilibrio ecológico. Se ditarão todas as normas necessárias para garantir a utilização e o aproveitamento da fauna, a flora, a terra e água, se realizem racionalmente, evitando depredação"

${ }^{46}$ Lei Florestal, Decreto no. 101-96 do Congresso da República Guatemalteca. Esta Lei está integrada por onze títulos que tratam, sucessivamente, as seguintes matérias: disposições gerais; órgão de direção e encarregado de aplicação da lei: conceições, bosques e sua proteção; aproveitamento, manejo e industrialização florestal; fomento de floresta, desenvolvimento rural das florestas; regime impositivo, controle e estatística; delitos e falta contra os recursos florestais; e disposições transitórias e derrogatórias. 


\section{Honduras:}

Em Honduras, como lei base na proteção do direito ambiental, temos a "Lei Geral do Ambiente de Honduras" (1993), estabelecendo alguns princípios gerais e definindo os seus objetivos: a) regula a gestão ambiental desde o ponto de vista da sua organização administrativa, criando entre outras coisas, uma Secretaria de Estado no Despacho do Ambiente ${ }^{47}$; b) estabelece regras para a proteção do ambiente e o uso racional dos recursos naturais, assim como para os elementos ambientais distintos dos recursos naturais, incluindo regras especiais para a proteção do meio ambiente e c) tipificando os delitos ambientais e as infrações administrativas.

No final da década de 90 , Honduras experimentou uma mudança muito importante em matéria penal para a regulamentação dos delitos ambientais, incorporando, em 08 de fevereiro de 1997, um capítulo sobre os delitos ambientais ao Código Penal (Decreto no. 1991-96). A despeito disto, pelo Decreto no. 59-67, de 10 de junho de 1997, derrogou-se este capítulo.

\section{Salvador:}

De conformidade com a Constituição da República, a proteção, a conservação e o melhoramento dos recursos naturais e o meio-ambiente devem ser objeto de legislação especial.

O texto constitucional, desta forma, remete-nos à Lei do Meio Ambiente do Salvador ${ }^{48}$ (1998), a qual está dividida em 14 Títulos, que se agrupam em 3 partes. A parte I contém as disposições gerais e as regras sobre gestão do meio ambiente, incluindo os instrumentos de política do meio ambiente, a dimensão ambiental e a prevenção e controle da contaminação ambiental. A parte II ocupa-se das disposições sobre recursos naturais renováveis, os ecossistemas e os recursos naturais não renováveis. Finalmente, a parte III está destinada à responsabilidade administrativa, civil e penal, incluindo os procedimentos das mesmas.

A mencionada legislação, em seu artigo 105, estipula a responsabilidade penal: "como conseqüência da infração às disposições estabelecidas na presente lei, incorrendo em delito, será sancionado de conformidade com o estabelecido no Código Penal e, no seu artigo 106, determina a ação penal e a define como pública, correspondendo seu exercício à Fiscalía General de la Republica, sem prejuízo de que as pessoas naturais ou jurídicas possam exercer o seu direito de ação pessoal conforme previsto na presente lei e no Código Processual Penal".

\footnotetext{
${ }^{47}$ Posteriormente suprimida por o Decreto número 218 - 96 que crio a Secretaría de Recursos Naturais ao Ambiente, com a Subsecretaría de Recursos Naturais e ambiente.

48 Decreto 233. Assembléia Legislativa da República do Salvador.
} 
Porém, o Código Penal da República do Salvador (Decreto no. 1030) destina o título $\mathrm{X}$ aos crimes relativos à ordenação do território, à proteção dos recursos naturais e ao meio ambiente, sancionando, em seu Capítulo I, com penas de um ano prisão ou dias multa aqueles que efetuarem construções não autorizadas (art. 253) ou funcionários públicos que outorgarem licenças contrárias às normas urbanísticas (art. 254).

O seu Capítulo II encontra-se destinado aos delitos relativos à natureza e ao meio ambiente, condenando com prisão as pessoas autoras de delitos de contaminação ambiental (art. 255), tanto agravada (art. 256), quanto culposa (art. 257). Assim como a pessoa que destrói, queima ou corta um bosque (art. 258), flora protegida (art. 259), fauna (art. 260) e fauna protegida (art. 261).

De sua parte, o art. 262 sanciona os funcionários públicos que omitam informações sobre algum delito ambiental.

\section{Panamá:}

O Panamá não conta com uma norma constitucional que estabeleça o Direito dos cidadãos a um ambiente saudável ${ }^{49}$. Porém, o artigo 115 da Constituição Política estabelece o dever do Estado, assim como de todos os habitantes do território Panamenho, de proporcionar um desenvolvimento social e econômico que previna a contaminação do ambiente, mantendo o equilíbrio ecológico e evitando a destruição dos ecossistemas.

Assim, o artigo 116 do mesmo texto legal estipula a função do Estado de regulamentar, fiscalizar e aplicar oportunamente as medidas necessárias para garantir a utilização e o aproveitamento da fauna terrestre, fluvial e marinha, assim como os bosques, as terras e a água.

A norma base sobre a proteção do ambiente no Panamá é a Lei número $41^{50}$ : Lei Geral do Ambiente, a qual está integrada pot 131 artigos que regulam, de maneira sucessiva, temas tais como seus fins, a política nacional do ambiente, a organização administrativa do Estado para a legislação ambiental, os instrumentos para a gestão ambiental, a proteção da saúde e sustâncias potencialmente perigosas, os recursos naturais, a responsabilidade ambiental, a investigação do delito ecológico, o órgão judicial e outras situações. Também encontramos diversos avanços nas políticas ambientais panamenhas na Lei Florestal ( 03 de fevereiro de 1994), na Lei 30 (30 de dezembro de 1995) e na Lei da Vida Silvestre (22 de setembro de 1996).

A legislação penal do Panamá estabelece direitos e responsabilidades em matéria ambiental, fixando a categorização da legitimação ativa em assuntos penais, civis e

\footnotetext{
49 A norma constitucional existente no regime ecológico tem outra conotação.

${ }^{50}$ Lei 41 de Julho de 1998 - Gaceta oficial 23. 578 de 3 de Julho de 1998.
} 
administrativas, no contexto jurídico nacional ou o princípio da Teoria dos Direitos Difusos, como meio idôneo para que a sociedade civil possa valer seus direitos. Estes princípios estão consagrados no artigo 111 da Lei 41 - a Lei Geral do Ambiente da República da República de Panamá.

Especificamente, a responsabilidade penal regula-se na Lei $24^{51}$ (07 de junho de 1995), "pela qual se estabelece a legislação de vida silvestre na República de Panamá e diramse outras disposições". Esta lei contempla multas e regulamenta violações com sanções de repressão da liberdade.

No entanto, no Projeto do novo Código Penal inclui-se um título denominado delito ecológico, o qual especificará os crimes e as penas aplicáveis.

\section{Nicarágua:}

A legislação ambiental nicaragüense está composta por uma série de instrumentos de gestão tais como leis gerais, leis específicas, decretos presidenciais, decretos ministeriais, normas técnicas obrigatórias nicaragüenses e ordenanças municipais.

$\mathrm{Na}$ Constituição Política da República de Nicarágua, o art. 60 estabelece o ..."dever do Estado de garantir o direito de habitar em um ambiente saudável. É obrigação do Estado a preservação, a conservação e o resgate do meio ambiente e dos recursos naturais".

A lei marco da Nicarágua é a Lei Geral do Meio Ambiente e dos Recursos Naturais de Nicarágua (1997), tendo por objeto "estabelecer as normas para conservação, proteção, melhoramento e restauração do meio ambiente e os recursos naturais que o integram" (artigo $1^{\circ}$.).

\section{Costa Rica:}

$\mathrm{Na}$ última década, o desenvolvimento da legislação ambiental costarriquenha tem sido impressionante. Há duas reformas constitucionais - arts. 46 e 50 - de leis importantes: como a Orgânica do Ambiente, a de Biodiversidade, a de Conservação de Solos e as novas leis em matéria florestal e vida silvestre, sendo um dos denominadores comuns desta evolução o estabelecimento de limites ao direito de propriedade e à livre iniciativa econômica. $\mathrm{Na} \mathrm{Costa}$ Rica, o direito de propriedade encontra-se reconhecido no art. 45 e no artigo 46, estabelecendose a liberdade de comércio ou livre iniciativa econômica, assim como a proteção da saúde, ambiente, seguridade e interesses econômicos, etc.

Ao lado destes artigos, na mesma Carta Magna, o artigo 50 estabelece o "direito a um ambiente saudável e ecologicamente equilibrado", prevendo o dever do Estado de "garantir, defender e preservar este direito".

${ }^{51}$ Leei 24 de 23 de Novembro de 1992 - Gaceta oficial 22.172 de 27 de Novembro de 1992. 
Em geral, a Costa Rica possui 8 (oito) normativas específicas ${ }^{52}$ em benefício da conservação do meio ambiente, assim como normativas gerais, na Constituição Política e nos Códigos Ambiental, Civil e Penal.

Depois da Conferência de 1992, continuou-se a tendência de estabelecer um marco jurídico para a política ambiental, diante da definição das leis gerais de princípios sobre a matéria, as quais deviam ser observadas nas atividades governamentais. No caso da Costa Rica, a lei básica ou marco para a proteção do meio ambiente é a Lei no. 7.554 - Lei Orgânica do Ambiente (1995), distribuindo seus 118 artigos permanentes em 22 Capítulos, os quais tratam de maneira sucessiva das seguintes matérias: a) disposições gerais da Lei; b) participação cidadã, educação e investigação ambientais; c) impacto ambiental, proteção e melhoramento do ambiente em assentamentos humanos; d) ordenamento territorial; e) áreas silvestre protegidas; f) recursos marinos, costeiro e úmido; g) diversidade biológica; h) recurso florestal; i) ar, água e solo; i) recursos energéticos, contaminação e produção ecológica; l) organização administrativa, financiamento e sanções; $m$ ) Controlador do Ambiente; n) Tribunal Ambiental Administrativo; o) disposições finais.

Mas as novidades encontram-se na legislação setorial, onde os últimos desenvolvimentos mostram um propósito de adequação à legislação propriamente ambiental, precisamente em temas como a política nacional ambiental - Lei sobre a Biodiversidade de 1998.

Toda forma de reparação do dano ambiental deve corresponder aos princípios de prevenção, correção da fonte e do poluidor-pagador. No caso costarriquenho, encontramos no art. 99 , inciso 'g' da Lei Orgânica do Meio Ambiente e no artigo 54 da Lei de Biodiversidade, a importância de restaurar o ambiente e sua biodiversidade no estado anterior à ocorrência do dano.

Em seu artigo 100, a Lei Orgânica do Ambiente 7.554 determina que a legislação penal, o Código Penal e as leis especiais estabelecerão as figuras delitivas correspondentes para a proteção do ambiente e da diversidade biológica. Tratando-se de delitos cometidos por funcionários públicos ou profissionais no exercício no seu cargo, a autoridade judicial poderá impor a pena de inabilitação especial por um máximo de 5 anos de acordo com os critérios gerais de imposição da pena.

No entanto, o artigo 30, inciso ‘’ do Código Processal Penal prevê como causa de extinção da ação penal, a reparação integral do dano particular ou social causado pelo delito, sempre que seja aceito pela vítima e admitido pelo Ministério Público. Desta forma, a restitutio in pristinum deve. ser sempre a primeira medida que se tem a procurar quando se produz o dano ambiental e unicamente quando tal reparação seja impossível realizar-se, seja pela irreversibilidade do dano ou pelo custo econômico desproporcionado, é que se recorrerá a ação penal.

52 Lei orgânica do meio ambiente de Costa Rica; Lei de Biodiversidade; Lei Geral de água potável; Lei de água; Lei florestal; Regulamento para a regulação do uso racional da energia; regulamento de cessão de direitos e obrigações de contratos de exploração de hidrocarburos; e o Acordo de cooperação ambiental entre o Governo da República de Costa Rica e o Governo da Canadá. 
Porém, o Código Penal Costarriquenho, em seus artigos do 257 a 262, sanciona com pena de prisão ou dias multa aquele destrua áreas ambientais protegidas e recursos naturais, contamine o ambiente, o ar, introduza ilegalmente substâncias tóxicas, assim como, qualquer delito contra a flora e a fauna silvestre.

$\mathrm{Na}$ Costa Rica, existe na atualidade o Projeto 14.899, que tem por objetivo buscar a interdição da impunidade por meio do fortalecimento e da especialização dos órgãos encarregados da justiça penal. Esta lei conhecerá de todos os delitos contemplados nas leis especiais encartegadas de normatizar os temas relacionados com o meio ambiente ou qualquer outro delito que possa prejudicar a flora, a fauna, a água e o solo. Esta possível jurisdição penal ambiental exercer-se-á em todos os juizados penais ambientais, incluindo os T'ribunais Superiores.

Desta feita, percebemos que. América Central, mesmo que seja um istmo com evidentes problemas sociais e econômicos, apresenta uma estrutura jurídica consciente das tiquezas naturais que possui, estabelecendo sanções tanto administrativas, como civis e penais àqueles que não respeitam ativa ou passivamente à natureza.

\section{CONCLUSÃO}

A título de conclusão, gostaríamos de trazer algumas reflexões do Prof. Gilberto Passos Freitas ${ }^{53}$, que nos explica grosso modo: "Para que a proteção do meio ambiente possa ser realmente eficiente devem os Estados limítrofes ou aqueles que por sua situação geográfica o exijam, estabelecer, como assinalado, programas de vigilância e controle e promover troca de informações, experiências e dados".

No caso do Mercosul, a inexistência de um sistema judiciátio, tem dificultado a aplicação das leis e de uma ação internacional na preservação dos ecossistemas que não podem ser tratados de acordo com divisas geográficas ou políticas, mas sim de forma integral sob pena de comprometimento das regras de proteção. Assim, propõe-se a criação de um Tribunal supranacional com Jurisdição Penal em todo o Mercosul para o julgamento de causas envolvendo os interesses dos países em nível público e privado.

Portanto, na Centro-América, observamos, no dia-a-dia, uma tendência a emissão de normas legais ambientais restritivas das atividades econômicas, mas, por outra parte, há uma corrente dirigida à desregulamentação e à facilitação das atividades empresariais e aos investimentos. O resultado é uma clara contradição, facilitando a evasão das normativas ambientais. Porém, a América Central aparece como um istmo consciente das crises geradas pelo predomínio de valores e práticas individualistas e agressivas para com o meio ambiente.

53 PASSOS DE FREITAS, Vladimir. Mercosul e Meio Ambiente, IN: Direito Ambiental em evolução, Editora Juruá, Curitiba, Brasil, 2002 
Por isto, é de suma importância disponibilizar normativas e capacitar juízes formados em uma ética baseada na solidariedade e uma sensibilidade que lhes permitam tratar de uma forma adequada os problemas ambientais.

Em geral, no continente Americano, dever-se-ão adotar medidas aliadas a uma política comunitária do meio ambiente para um desenvolvimento direcionado não só a uma real melhoria da qualidade de vida, como para um maior crescimento econômico, uma vez que as sanções penais não resultam suficientes, nem compensatórias com os prováveis danos causados a natureza, os quais, na maioria dos casos, são irreversíveis.

\section{BIBLIOGRAFIA}

ARAUJO, João Marcello de, Regionalização do direito penal no Mercosul (Contribuição para a Historia Jurídica do Mercosul) In Revista de Derecho del Mercosur. Buenos Aires, La Ley, 1997.

ARAUJO, Nadia de. Código do Mercosul - Tratados e legislação. Rio de Janeiro: Renovar, 1998

ATRI, Diana. Harmonização e Integração em assuntos no meio ambiente no Mercosul (Harmonizacion e Integracion medioambiental em el Mercosur) In revista de Derecho del Mercosur. Buenos Aires, La Ley, 1998

BERTUCCI Rosana, CUNHA Eldis, CUNHA Tarciso, DEVIA Leila, FIGUEIRAS Marcos, RUIZ DIAZ Roberto, VIDAL PERERA Raquel, Mercosur y Médio Ambiente, Ediciones Ciudad Argentina, Buenos Aires, 1996

BERTUCCI SIQUEIRA, Rosana. "Instrumentos judiciais do cidadão em defensa do meio ambiente nos países do Mercosul" In Revista de Direito Ambiental N.4, São Paulo, 1998

Bittencourt, Cezar Roberto. Responsabilidade Penal da Pessoa Jurídica, Boletim do IBCCrim, São Paulo, abril/98, n. 65, pág. 7 .

CAPPELLI, Silvia. Aulas proferidas na cadeira de direito ambiental dentro do curso preparatório à carreira do Ministério Público, Porto Alegre/RS, 2002

CARO CORIA, Dino Carlos. "Derecho Penal del ambiente. Delitos e Técnicas de

Tipificação" Parte Especial, pág. 1105 - 1006, décima sexta edição, Dikynson, Madrid, 1993.

CASELL, Paulo Borba. Codigo do Mercosul -- Tratados e legislação. Rio de Janeiro: Renovar, 1998

Dotti, René Ariel, A responsabilidade Penal das Pessoas Jurídicas, Revista de Ciências Criminais n. 11, São Paulo, pág. 201 
HURTADO POZO, José. "Manual de Direito Penal.". Parte Geral, reimpresão da segunda edição, Eddili, Lima, 1987

MACHADO, Paulo Affonso Leme. Direito ambiental brasileiro. 7 ed. São Paulo: Malheiros, 1998

MORATO LEITE, José Rubens. BUZAGLO DANTAS, Marcelo. Os instrumentos de proteção ambiental e o mercosul. In Revista dos Tribunais; São Paulo, 1996. V.725, P.39-48

PASSOS DE FREITAS, Vladimir. Mercosul e Meio Ambiente IN Direito Ambiental em evolução, Editora Juruá, Curitiba, Brasil, 2002.

PURVIN DE FIGUEIREDO, Guilherme. "Crimes ambientais e responsabilidade penal objetiva” IN: http://www.direitopenal.adv.br/artigos.asp?pagina $=22 \&$ id $=697$

SHECARIA, Sérgio Salomão - Responsabilidade penal da pessoa jurídica, $1^{2}$ ed., $2^{\mathrm{a}}$ tiragem. São Paulo: Revista dos Tribunais, 1999

SCHEIBE, Virginia da Cunha. Direito Ambiental no Mercosul, palestra proferida no IV

Congresso de Direito ambiental promovido pelo Centro de Estudos Judiciários do Conselho da Justiça Federal, Brasilia, 10.05.2001

SILVA, Geraldo da: LAVORENTI, Wilson: GENOFRE, Fabiano. Leis Especiais Anotadas, 2da edição, editora Impresa, 2001

SIRVINKAS, Luís Paulo. Tutela Penal do Meio Ambiente. São Paulo: Saraiva, 1998, pp 2223; MACHADO, Paulo Affonso Leme. Direito Ambiental Brasileiro 7 ed. São Paulo: Malheiros, 1998, pp 593-598

SOUZA, João Ricardo Carvalho de. Constituição Brasileira e Tribunal de Justiçado Mercosul. Curitiva: Juuá, 2001

ZAVALA, Sheila Abed e FAELLA Ricardo Merlo. Guia de derecho ambiental Del Paraguay. Assunção: IDEA - Instituto de Derecho Ambiental, 1999. 